Чаще других (30\% от общего числа проектов) в реальный сектор экономики внедряются разработки ученых Москвы. На втором месте Мордовия, на третьем СанктПетербург. В десятке лидеров Ставропольский край, Республика Татарстан, Ростовская, Нижегородская, Московская, Новосибирская и Свердловская области, в совокупности составляя $20 \%$.

Таким образом, в науке существуют определенные проблемы, главные из которых представлены ниже.

- Слабое государственное финансирование (в \% от ВВП по сравнению с ведущими мировыми державами).

- $\quad$ Научные публикации в большей массе на русском языке (а равно и плохое знание российскими учеными английского).

- Недостаточная профессиональная мобильность российских ученых.

- $\quad$ Пропасть между наукой в ВУЗах и наукой в учреждениях РАН.

- $\quad$ Разрыв и отставание между наукой в центрах и регионах.

- $\quad$ Ведомственные реформы, зачастую серьезно вредящие развитию науки.

- $\quad$ Битва титанов на верхах (Академия против министерств и ведомств)

- Малоэффективное институтское образование (причем именно в плане профориентации и интеграции в реальную работу)

- Отсутствие преемственности между научной школой современных НИИ и ранее существующих. [2]

В любом случае прогноз развития российской науки скорее оптимистический. Проблемы функционирования науки не только выявлены и обозначены руководством РФ и научным сообществом, но над ними работают и стараются решать. Насколько успешно покажет время. В некоторых областях Россия уже обладает прорывными мировыми технологиями. Надежда на то, что Российские ученые еще покажут свой потенциал и выйдут в мировые лидеры, остаётся.

$$
* * *
$$

1. Долгих Е.А., Паршинцева Л.С. Статистический анализ развития науки в секторе высшего образования // Вестник университета. 2020. № 2. С. 92-96.

2. Долгих Е.А., Першина Т.А. Кадровый потенциал науки и его анализ // Проблемы российской экономики на современном этапе. Материалы всероссийской научно-практической конференции. Москва, 2020. С. 238245.

3. www.issek.hse.ru - Институт статистических исследований и экономики знаний URL: https://issek.hse.ru/news/442044357.html (дата обращения: 6.12.2021)

4. www.gks.ru - Федеральная служба государственной статистики URL: https://rosstat.gov.ru/folder/14477 (дата обращения: 8.12.2021)

\title{
Клишина К.А. \\ Направления трансформации системы высшего образования России для эффективного социально-экономического развития страны
}

Московский государственный технический университет им. Н.Э. Баумана

(Россия, Москва)

doi: 10.18411/trnio-01-2022-93

\section{Аннотация}

Данная статья посвящена исследованию системы высшего образования в России и ее влиянию на социально-экономическое развитие страны.

Целью статьи является анализ системы высшего образования в России, исследование проведенных и возможных реформ в данной области, построение вектора развития системы с учетом скорости технологического прогресса и зарубежного опыта.

Объектом исследования статьи является система высшего образования в России.

В соответствии с указанной целью статьи наиболее важными результатами являются: 
1) проанализировано современное состояние системы высшего образования России;

2) рассмотрены реформы и перспективные направления развития в системы высшего образования России;

3) даны рекомендации по развитию системы высшего образования с учетом факторов, тормозящих данный процесс.

Ключевые слова: высшее образование, система высшего образования, высшее образование в России, российская система высшего образования.

\section{Abstract}

This article is devoted to the study of the higher education system in Russia and its impact on the socio-economic development of the country. The purpose of the article is to analyze the higher education system in Russia, to study the conducted and possible reforms in this area, to build a vector for the development of the system, taking into account the speed of technological progress. The object of the research of the article is the system of higher education in Russia. In accordance with the stated purpose of the article, the most important results are: 1) analyzed the current state of the higher education system in Russia; 2) considered reforms and promising directions of development in the higher education system in Russia; 3) recommendations are given for the development of the higher education system, taking into account the factors that inhibit this process.

Keywords: higher education, higher education system, higher education in Russia, Russian higher education system.

В связи с быстрыми темпами научно-технического прогресса, в наши дни информация устаревает очень быстро, что сказывается на эффективности обучения в университетах. Качество обучения падает, так как образовательная программа пока не может модернизироваться также быстро, как обновляется информация и развиваются технологии. Поэтому сейчас в России и в Европе высшее образование напоминает своего рода «конвейер», который пропускает через себя большое количество студентов, дает знание, но на выходе не всегда получается то, что планировалось изначально. Очень часто студенты не знают, как применять свои знания именно с практической точки зрения, что является как раз недостатком конвейерного тип обучения.

Коммерциализация высшего образования в России внесла негласное условное разделение университетов на «элитные» и не являющиеся такими. Сейчас существует проблема заинтересованности населения именно в самом дипломе, а не в полученных знаниях. Стало престижно иметь диплом, учиться в ведущих Московских университетах, поступать на дорогие специальности, хотя основная цель высшего образования - это получение фундаментальных знаний и практических умений, позволяющих найти достойную работу и принести пользу своей стране и обществу.

Стереотипное мышление общества в вопросе образования после окончания школы снизило заинтересованность населения в колледжах и специализированных техникумах, хотя данные учреждения нуждаются в неменьшем развитии, чем университеты. Там готовят людей рабочего класса: электриков, слесарей, механиков и других представителей бесспорно достойных профессий. На данный момент в России уже наблюдается нехватка действительно достойных профессионалов в данных отраслях, что в корне неправильно.

Из этого можно сделать вывод, что образование нужно развивать в комплексе, развивая все учебные заведения, дающие полезные навыки и знание, и снабжающие рынок труда квалифицированными кадрами.

Мировой рынок образовательных услуг формируется под влиянием наиболее развитых национальных систем мира, одной из которых выступает российская система высшего образования, являющаяся источником формирования национальной интеллектуальной элиты, научных, образовательных, технических кадров, составляющих сегодня основную движущую силу цивилизационного роста российской экономики и 
общества в целом. И нам важно не утратить существенные преимущества в образовательной сфере, стремясь приспосабливаться под существующие в мире системы. Важной задачей является изучение позитивного мирового опыта и использование его для совершенствования национального образовательного процесса, учитывая особенности нашей страны.

В обеспечении успешной деятельности зарубежных университетов важную роль играют маркетинг и брендинг. Каждый университет формирует и поддерживает свой позитивный образ и бренд - визитную карточку вуза, стремится быть привлекательным для своих целевых аудиторий, в качестве которых выступают абитуриенты, студенты, работодатели, инвесторы, органы власти.

Например, университеты США очень заинтересованы в брендинге и своей репутации, во многом еще потому, что очень многие университеты США являются частными, а не государственными, и существуют на деньги от платы за обучение студентов и частные инвестиции. Стоит отметить, что высшее образование в США является платным для всех граждан в любом университете, не зависимо от того, государственный он, или частный. Обучение в частных университетах стоит дороже, чем в государственных в связи с тем, что они обеспечивают себя полностью самостоятельно без помощи государства. В последние годы в США наблюдается тенденция заинтересованности населения в частных университетах, чем в государственных, так как частные университеты направлены на достижение конкретного результата, что приводит к выпуску крайне профессиональных кадров, в которых заинтересованы многие работодатели. Одними из самых известных частных университетов США являются Гарвард и Стэнфорд. Интересным является и подход в американской системе обучения. Студент может сам набирать предметы, которые он хотел бы изучить, может выбрать класс и преподавателя, что делает его автономным и независимым, а отношение преподавателей к студентам не предвзятым. То есть основным отличием от российской системы образования является отсутствие как таковых групп студентов, каждый студент существует в рамках университета обособленно.

В России все университеты преимущественно являются государственными, частные существуют, но их совсем немного. До 2010 года в России появилась большая масса частных университетов, целью которых стало извлечение прибыли, а не качественное обучение студентов. Государство забило тревогу, когда на рынке стали появляться совсем неопытные выпускники частных университетов, совершенно не подготовленные к рабочей деятельности. Поэтому вынужденной меры со стороны государства было избавление от такого количества частных высших учебных заведений, приостановление деятельности многих государственных университетов и их филиалов и взятие под строгий контроль эффективность работы образовательных учреждений. Поэтому на данном этапе модель США, в которой активно и успешно развиваются частные университеты, нам не подходит. На данном этапе России следует уделять пристальное внимание деятельности действующих университетов, финансировать и развивать их.

Система высшего образования во многих Европейских странах во многом схожа с нашей, так как практически все Европейские страны являются участницами болонского процесса, накладывающего на всех участников многие схожие черты в образовательной деятельности. В Европе также до сих пор действует разделение уровней образования на магистратуру и бакалавриат. Но сейчас все чаще встречаются специальности и направления, которые сокращают срок обучения. Например, самыми популярными схемами обучения в Европе являются «3+2» и «4+1», то есть три года обучения в бакалавриате, два года обучения в магистратуре, или четыре года обучения в бакалавриате и один год обучения в магистратуре. Сокращение срока программ было вызвано упразднением ряда предметов, которые были лишними и не давали нужных знаний по данным направлениям подготовки. Хотелось бы отметить, что одной из проблем российской системы высшего образования как раз является переполненность программы обучения предметами, которые, как правило, далеко не все нужны для образовательного процесса в тех, или иных направлениях. 
Главными преимуществами европейского и американского образования является упор на практику, что является очень важным при подготовке настоящих профессионалов. Действительно, в России не хватает упора на практику, что сказывается при поиски студентами работы. Далеко не каждый студент может самостоятельно усвоить и преобразовать теоретические знания в практические.

Еще одной отличительной особенностью зарубежных систем образования является ориентированность на знания и навыки студента, поэтому в университетах США и Европы сравнительно небольшой процент студентов, получающих диплом. Им важно выпустить профессионалов, а не просто отдать диплом. Такая политика является на мой взгляд правильной. В России было бы весьма неплохо ужесточить порядок получения дипломов.

Говоря о зарубежном опыте, можно отметить еще один интересный факт - в США проводятся анонимные опросы студентов, в которых они могут высказать свое мнение о работе преподавателей и курсах. Результаты такого тестирования строго засекречены, обсуждаются на закрытых заседаниях кафедры и служат основанием для совершенствования содержания преподаваемых курсов, методики преподавания, преподавательского рейтинга.

В США существует преподавательский рейтинг, который составляется с учетом мнения студентов о преподаватели и о методах его преподавания. Этот рейтинг носит весьма серьезный характер, так как за низкий рейтинг могут последовать меры вплоть до увольнения.

Если говорить о преподавателях в российских университетах, стоит отметить, что в России предъявляются слишком завышенные требования к научно-педагогическим кадрам. Они включают в себя огромное количество бумажный работы, так как в российских университетах процветает бюрократия, большое количество выпускаемых научных публикаций за определенный срок в обязательном порядке, участие в конференциях и прочее. Следует понимать, что такая система не приведет к большей эффективности преподавателей в их основной деятельности - преподавании. Необходимо уделять внимание не количеству написанных публикаций или изданных статей, а качеству и эффективности обучения студентов, что должно являться для преподавателей первоочередным. Большая нагрузка преподавателей, не связанная с обучением студентов, негативно сказывается на самом процессе обучения.

Возвращаясь к процессу, обучения хочется отметить, что очень важным в наше время является обучение на английском языке, который является международным. Знание английского языка сейчас стоит на одном уровне с профессиональными навыками и умениями, так как делает из студента универсального кадра, готового работать в международных компаниях, представлять свою компанию за рубежом, быть задействованным в международных проектах, в полной мере использовать возможности электронных образовательных ресурсов на иностранном языке для собственного развития в профессиональной области.

Одним из способов решения задачи по подготовке специалиста, соответствующего перечисленным требованиям, может являться принятие университетами принципа интеграции профессиональных дисциплин и иностранного языка как ключевого принципа современного высшего образования. Этот принцип означает подготовку специалист, свободно владеющего английским языком как на уровне повседневного общения, так и профессионального в рамках своей специальности.

Существует интегрированный предметно-языковой подход (CLIL - Content and Language Integrated Learning), преследующий основной целью одновременного изучения иностранного языка и профессиональной дисциплины и подразумевающего развитие практической функциональности языка при решении профессиональных задач.

На настоящий момент CLIL-подход считается одним из наиболее успешных методов преподавания благодаря тому, что обладает рядом преимуществ. Такими преимуществами являются: практическая направленность обучения; возможность погружения в языковую среду; раскрытие функциональности языка. 
В результате реализации интегрированного предметно-языкового подхода на базе высшего образования будущий специалист (выпускник вуза) будет обладать следующими конкурентными преимуществами: возможностью обмена опытом на международном уровне и повышения квалификации за рубежом; неограниченным доступом к информационным ресурсам на иностранных языках; ростом стремления к самореализации в профессиональной области; готовностью и способностью к саморазвитию в языковой и профессиональной сферах; большими возможностями для получения высоких результатов при сдаче экзаменов на сертификаты международного образца, определяющие уровень владения иностранного языка; готовностью к непрерывному обучению; высокой конкурентоспособностью. Следовательно, принимая во внимание преимущества CLIL-подхода для подготовки специалистов, отвечающих современным условиям рынка труда, можно убедиться в целесообразности его применения на уровне высшего образования России. CLIL-подход зародился в Европе в 1990-х годах и по настоящее время активно используется на всех ступенях обучения (начальной, средней и высшей).

Подводя промежуточный итог хочется отметить, что России стоит использовать зарубежный опыт в развитие отечественной системы образования. Основными идеями данного опыта в рамках его применения в России являются:

1) осовременивание образовательных программ, сокращение количества читаемых предметов и сокращение срока обучения;

2) ужесточение процесса получения диплома;

3) переориентация образования с теории на практику;

4) модернизация деятельности преподавательского состава с заданием первичной и самой значимой цели - качественного обучения студентов;

5) привлечение работодателей в разработку образовательных программ;

6) активное внедрение современных технологий в систему высшего образования.

Россия является одним из лидеров в мире по доле взрослого населения с высшим образованием, а также по количеству лет (в среднем), проведенных человеком в системе формального образования. Но уникальность России заключается в том, что зачастую профессионализм людей, имеющих высшее образование недостаточно сильно отличается от уровня людей, не имеющих высшее образование (по данным исследования РІААС). Невысокая эффективность высшего образования связана во многом с университетами и программами обучения в них, имитирующие образовательный процесс, что снижает уровень качества получаемых умений и навыков. На такой неутешительный прогноз государство отреагировала сокращением количества высших учебных заведений на рекордные 42,2\% (в период с 2013 по 2017 гг.), более чем на треть уменьшилось количество филиалов университетов. Такая мера помогла перебороть получение студентами некачественного высшего образования и сфокусировать силы государства на определенном количестве университетов, готовящих настоящих профессионалов.

Устаревшие и достаточно жесткие требования к преподавателям не позволяют выстраивать образовательные программы таким образом, чтобы они отвечали запросам работодателей и страны в целом. Отсутствуют стимулы для построения современных моделей отношений внутри университета, и речь не только про отношения «преподавательстудент», но имеются ввиду еще работодатели, которые будут заинтересованы в развитии системы высшего образования посредством участия в формировании образовательных программ и стажировок для студентов, как потенциальных работников.

Распространенность очных и заочных образовательных программ низкого качества значительно уменьшает общую эффективность государственных и частных вложений в систему высшего образования России. Обучение на некачественных программах высшего образования в разы увеличивает разрыв с более успешными сверстниками на старте карьеры, что, с одной стороны, порождает социальное неравенство, а с другой — снижает престиж высшего образования в стране. 
Мировой опыт показывает, что качество высшего образования должно быть одинаково и равномерно на всей территории страны (США, Европа, Китай, Корея и др.). Это является очень важным замечанием, так как в России основное внимание уделяется именно московским высшим учебным заведениям и университетам, отсюда такой большой разрыв в качестве образования у субъектов Российской Федерации.

Система высшего образования является полноценным экономическим агентом, который вносит существенный вклад в ВВП (валовой внутренний продукт). Поэтому так важно заниматься развитием и усовершенствованием системы высшего образования. Существует прямая зависимость уровня высшего образования в стране и уровня социальноэкономического развития. Чем выше уровень образование, тем более развитой является страна.

Стоит также отметить, что на данном этапе в России возлагается непомерная нагрузка на преподавательский состав университетов. Бюрократизация образования предполагает большой объем бумажной работы для преподавателей, которая не позволяет в полной мере уделять время образовательному процессу, что негативно сказывается на качестве образования, снижая его. Следует оптимизировать работу преподавательского состава, дав возможность уделять больше времени научной и образовательной деятельности, курсам повышения квалификации.

Для устойчивого повышения качества образования по всей стране необходимо обеспечить университеты всеми необходимыми передовыми разработками. В большинстве университетов нет системы поддержки научной деятельности, хотя нашей стране нужны конкурентоспособные разработки и инновации. Следует уделять внимание создание научных кластеров, лагерей по всей России, для вовлечения молодого поколения в науку. За молодыми умами будущее, и с этим трудно поспорить. Россия нуждается в крепком научном пространстве, в котором будут заинтересованы школьники и студенты, так как существует проблема утечки молодых и перспективных умов на Запад и в Азию. Чтобы не растерять весь свой интеллектуальный потенциал России следует принимать методичные и быстрые шаги по развитию высшего образования.

Структура подготовки, исследований и разработок в университетах должна быть ориентирована на перспективные потребности рынка труда, что предполагает модернизацию образовательных программ, так как на данный момент, выходя из университетов, у студентов не всегда есть представление о том, как применить их знания на практике.

Университеты должны стать центрами интеграции интересов отраслевых высших учебных заведений и производств, научных организаций и региональных предприятий в рамках формирования новых образовательных программ и технологий их реализации. Такую же роль для национально распределенных отраслей должны играть опорные отраслевые университеты и программы.

Основные меры по развитию российской системы высшего образования к 2030 году.

1) Передача под управление университетов бизнес-инкубаторов, инновационных парков, технопарков. Развитие новых научных пространств по всей России, обеспечение их эффективного функционирования.

2) Разработка онлайн-программ обучения в рамках получения высшего образования. Предполагается, что такой формат обучения будет идти в дополнение к обычным занятиям, тем самым расширяя горизонт получения знаний для студентов. Цель данных онлайн-курсов - передача необходимой информации по тому или иному предмету вне зависимости от местонахождения университета, то есть студент любого российского высшего учебного заведения сможет получить доступ к курсу преподавателя любого Московского университета и получить необходимые знания, не выезжая за пределы места своего проживания.

3) Грантовая поддержка высших учебных заведений России, финансирование образовательных проектов, разработка комплексных подходов по 
обеспечению достойного финансирования всех образовательных учреждений.

4) Разработка и запуск конкурса получения грантов по модели «1+3», предполагающей семилетнее финансирование исследований и разработок одного ведущего научного центра или исследовательского университета и трех региональных университетов. В каждом региональном университете создается лаборатория, кадровое и научное руководство. При этом финансирование делится на паритетной основе между исследовательским университетом и региональными участниками программы. Исследовательский университет отвечает за результаты проведенной работы и должен на выходе предоставить достойные научно-исследовательские результаты, которые позволят России продвинуться в мировых рейтингах по уровню высшего образования.

5) Создание программы поддержки 100 университетов-лидеров в области комплексных программ развития экономики регионов и программы поддержки 25 университетов — лидеров развития отдельных отраслей (транспорт, медицина, сельское хозяйство, промышленность и др.). По данной программе университеты должны получать финансовую поддержку со стороны государства, которая должна включать в себя помимо финансирования деятельности университета стимулирование инициативы студентов в сфере предпринимательства, разработки инновационных технологий, научных открытий. При этом должны учитываться региональные особенности и постоянно обновляться образовательные процессы. Важным инструментом для этого является создание университетских венчурных фондов.

6) Запуск программы грантовой поддержки выпускников аспирантуры и учащихся ведущих научных центров, готовящихся занять позиции преподавателей и научных сотрудников университетов. Грант предполагает 5-летнее финансирование исследовательского проекта и академической мобильности (2 месяца в году).

7) Создание совместных образовательных программ магистратуры и аспирантуры между университетами и ведущими предприятиями, инвесторами и инновационными стартапами по приоритетным направлениям научно-технологического развития страны.

8) Формирование фокус-группы, чье внимание будет уделяться решению проблем социально-экономического развития регионов России, в эту фокусгруппу предполагается включать региональные университеты.

9) Расширение нормативных возможностей финансирования деятельности университетов в интересах регионов.

Дополнительные меры, поддерживающие реализацию основных мер.

1) Модернизация формата работы преподавательского состава и разработка новых программ по переподготовке кадров, которая будет акцентирована на современных технологиях и инновациях.

2) Организация образовательных поездок и стажировок студентов и преподавателей. Для этого должна быть хороша проработана межвузовская связь и привлечены для сотрудничества работодатели крупных фирм.

3) Разрушение барьеров по выстраиванию индивидуальных направлений образовательного процесса с учетом индивидуальных способностей, достижений и опыта учащегося (с активным вовлечением в формирование этих направлений работодателей). 
4) Развитие дистанционного образования с использованием инструментов онлайн-обучения с целью расширения возможностей студентов в получении высшего образования.

5) Разработка специальных квалификационных экзаменов для объективной оценки полученных знаний студентов и выпускников высших учебных заведений. Добровольная оценка уровня навыков и знаний осуществляется после прохождения отдельных курсов и модулей с непосредственным участием работодателей, участвующих в разработке данных программ и курсов (в том числе на базе инфраструктуры поддержки непрерывного образования).

6) Создание специализированных центров оценки качества обучения и образовательных результатов, обновление оборудования на регулярной основе в соответствии с передовыми технологиями в соответствующих отраслях экономики.

Результаты реализации мероприятий по направлению развития высшего образования к 2030 г. и количественные результаты и прямые их достижения к 2030 г.

1) Увеличение доли выпускников университетов, которые остаются в регионах и реализуют там свои инновационные проекты, пользуясь региональной поддержкой, в том числе финансовой.

2) Все студенты без исключения имеют возможность разработать свой собственный бизнес-проект и реализовать его, используя профессиональную поддержку со стороны преподавательского состава и работодателей.

3) Во всех университетах, которые являются центрами инноваций в регионах и отраслях, сформировано новое кадровое «ядро перемен», включающее молодых преподавателей, для проектов с ведущими вузами страны и обеспечивающими поддержку онлайн-курсов ведущими университетами.

4) Увеличение объема НИОКР (научно-исследовательские и опытноконструкторские работы) в расчете на одного студента в университетах и объема НИОКР в интересах заказчиков, которыми являются предприятия и организации, территориально расположенные в том же регионе).

5) Формирование достойной заработной платы для студентов во всех регионах России. Она должна быть не ниже средней по региону в течение первых трех лет работы, а затем увеличиваться.

6) Все российские студенты имеют доступ к общей образовательной платформе, на которой в свободном доступе находятся онлайн-лекции и семинары на базе ведущих российских и зарубежных университетов.

России:

Экономические эффекты и выгоды от развития системы высшего образования в

1) ускорение темпов экономического развития регионов (особенно регионов с замедленными темпами экономического роста);

2) увеличение охвата населения высшим образованием и системой повышения квалификации в рамках проекта по непрерывному образованию в течение всей жизни;

3) уменьшение доли численности студентов, работающих не по специальности, в связи со слабым ознакомлением практической стороны деятельности, на которую они учились;

4) создание высокопроизводительных рабочих мест и рост инновационной активности на региональном уровне. Технологическое обновление на предприятиях региона повлечет увеличение добавленной стоимости их продукции.

Прочие эффекты от развития высшего образования в России:

1) повышение уровня вовлеченности и удовлетворенности студентов; 
2) усиление социальной мобильности.

Грамотные и своевременные меры, направленные на развитие системы высшего образования смогут в обозримом будущем сделать российскую систему высококонкурентной в сфере высшего образования, что позволит значительно увеличить научный потенциал страны и повысить уровень социально-экономического развития России.

Данная статья носит лишь рекомендательный характер и представляет собой достаточно идеализированную картину образовательного будущего России. Всегда нужно учитывать тот фактор, что в реальности существует много сдерживающих, а иногда и неожиданных факторов. К неожиданным факторам можно отнести пандемию, которая нанесла непоправимый ущерб экономике нашей страны, последствия пандемии будут тянуться еще не один год, полностью оправиться от такого удара практически невозможно, нужно научиться существовать в данных условиях и развиваться дальше.

За высшим образованием будущее всех стран мира, именно высшее образование формирует пласт людей, которые в будущем станут управленцами, предпринимателями, учеными, врачами, преподавателями и т.д. И только от того, насколько эффективной будет система образования, зависит уровень профессионализма этих людей. Главная инвестиция любого государства в перспективное будущее своей страны - финансовые вложения в образовательную сферу.

$$
* * *
$$

1. Паспорт национального проекта «Образование» 2019-2024 гг.

2. Абанкина И.В., Беликов А.А., Гапонова О.С., Дудырев Ф.Ф., Корешникова Ю.Н., Коршунов И.А., Косарецкий С.Г., Мерцалова Т.А., Нисская А.К., Платонова Д.П., Сорокин П.С., Таловская Б.М., Фрумин И.Д. Глобальная конкурентоспособность российского образования. Материалы для дискуссии. (Сер.: Современная аналитика образования. № 3 (20)). М.: НИУ ВШЭ, 2020.

3. Галактионова, Ю.Ю. Состояние системы образования в современной России и прогнозирование ее дальнейшего развития / Ю.Ю. Галактинова // Аллея науки. 2019. Т. 4. № 1 (17). С. 795-797.

4. Гохберг Л.М., Озерова О.К., Саутина Е.В., Шугаль Н.Б. Образование в цифрах. Краткий статистический сборник 2020. М.: НИУ ВШЭ, 2020.

5. Прокудина, Е.Д. Сравнительный анализ систем образования в России и за рубежом / Е.Д. Прокудина // Интеграция наук. 2019. № 6 (10). С. 98-105.

6. Соколова, Е.В. Модернизация российской системы образования в современных условиях развития общества / Е.В. Соколова // Дельта науки. 2020. № 1. С. 82-84.

7. Яновская О.Г., Рыбина Г.А. Российское образование в контексте «экономики знаний» // Педагогика и просвещение. 2015. №2 (18).

\section{Ковтун Б.А., Желудкова Ю.М. \\ Особенности кредитования малого бизнеса в России}

ФГБОУ ВО Дальневосточный государственный университет путей сообщения(СахИЖТфилиал ДВГУПС в г. Южно-Сахалинске) (Россия, Южно-Сахалинск)

doi: 10.18411/trnio-01-2022-94

\section{Аннотация}

Кредитование субъектов малого бизнеса является одним из важнейших сегментов сферы деятельности банковского сектора экономики государства. Развитие системы кредитования малого бизнеса способствует повышению финансовой грамотности и осведомленности предпринимателей, кредитные учреждения формируют более разнообразные кредитные программы, а государство расширяет объемы мер поддержки и поддерживает инфраструктуру для существования эффективной деятельности среднего и малого бизнеса.

Ключевые слова: малый бизнес, кредитование бизнеса, льготные кредиты для бизнеса, кредитование малого бизнеса в период пандемии. 